\title{
US free markets less than free
}

The United States, the land of free enterprise, seems to be curiously illogical in its continuing belief that markets in some commodities should be less than free

SHould Eastern Europe and the Soviet Union look as confidently as they do towards the United States for a model of how the free-market system functions? Not necessarily, if some recent US economic behaviour is to be taken seriously. By now, the whole world knows how troublesome it has been for the Congress to arrive at an acceptable gasoline tax in this year's federal budget; in the end, it settled for a mere 5 cents a US gallon, making a total federal tax of 14 cents a gallon and leaving the cost of gasoline much lower than on the world's spot markets.

But there is worse. As if recognizing that gasoline in the United States will still be cheaper than it should be, the Congress has clapped a tax on motor-cars that fail to yield their drivers at least 23.5 miles for every US gallon. The result will not be a free market in gasoline consumption, but one in which patterns of consumption are skewed by contradictory and illogical forces.

That the price of gasoline should be a contentious issue is no surprise, of course. Last week's protests in Hungary, which took the form of huge traffic jams that can only have increased the cost of travelling, are a sufficient proof of that. The rest of Eastern Europe will find the going hard this winter, as the Soviet Union requires payment for its supply of oil in hard currency and as the governments of Eastern Europe begin living with the reality that they can no longer print banknotes to let their people buy the goods they need. Yet the price that angers Hungarians is roughly twice the going price of gasoline in the United States, where there is almost as vivid a sense that its price has been unjustly ramped up.

Yet there should be no doubt, in a true free market, what the price of gasoline should be. It must, for example, exceed the marginal cost, or that of producing a small extra amount of it. Otherwise there would be no reason why those who refine petroleum should continue to operate their distillation plant and catalytic crackers. This explains why gasoline prices have been rising in the past few months; uncertainty over the course of events in the Persian Gulf has raised doubts about the continuity of a large part of the world's supply of crude oil, so that those trading in this market are now less willing to part with oil they happen to own because they expect to be able to sell it for an even higher price if there should be physical shortages of crude in the next few months. This is not merely consistent with what the textbooks say, but also with the outcome of the British government's investiga- tion of the sharp increases in the price of gasoline from British petrol pumps during September. It is true that oil companies lucky enough to control cheaper supplies can hope to profit hugely at times like these, but that is their good fortune (which may nevertheless be abated by taxation) and their chief incentive for opening up other sources of supply.

Evidently this elementary lesson is not generally appreciated in the United States. For one thing, there is general grumbling that higher gasoline prices will cause hardship to many social groups, and that prices should be kept in check for that reason. The complaint is true, but the way to take the edge off social hardship is not to shield all gasoline consumers from higher prices, but to give extra cash to those who need it. For another, in the closely related field of energy supply in general, there is a whole regulatory apparatus, at the federal and state level, designed to relate the prices charged for energy to average rather than marginal costs. This is the effect of the procedures by which the prices charged by public utilities for commodities such as natural gas are fixed with reference to the overall profitability of the supplier, for example. It is curious that the land of free enterprise should so shield people from market reality.

This is the spirit in which the 'gas-guzzler' tax that has won the favour of both parties in the Congress should be seen for what it is - as a kind of moral statement of opinion about the ownership of inefficient motor-cars rather than a contribution to the management of a quickly changing energy market or, as some claim, as a contribution to the abatement of carbon-dioxide emissions.

\section{Utah confusion}

The time has come for decisive action by Utah's Fusion Advisory Committee.

IN the 18 months since cold fusion was first brought into the world by Stanley Pons and Martin Fleischmann, the original evidence for the phenomenon has become tenuous to the point of invisibility. The tritium evaporated and the gamma rays disappeared. Then the central claim, for excess heat generation, began to look shaky.

And now Stanley Pons himself is becoming scarce. A 